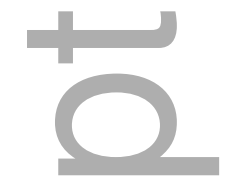

Relations Among Psychopathy, Moral Competence, and Moral Intuitions in Student and
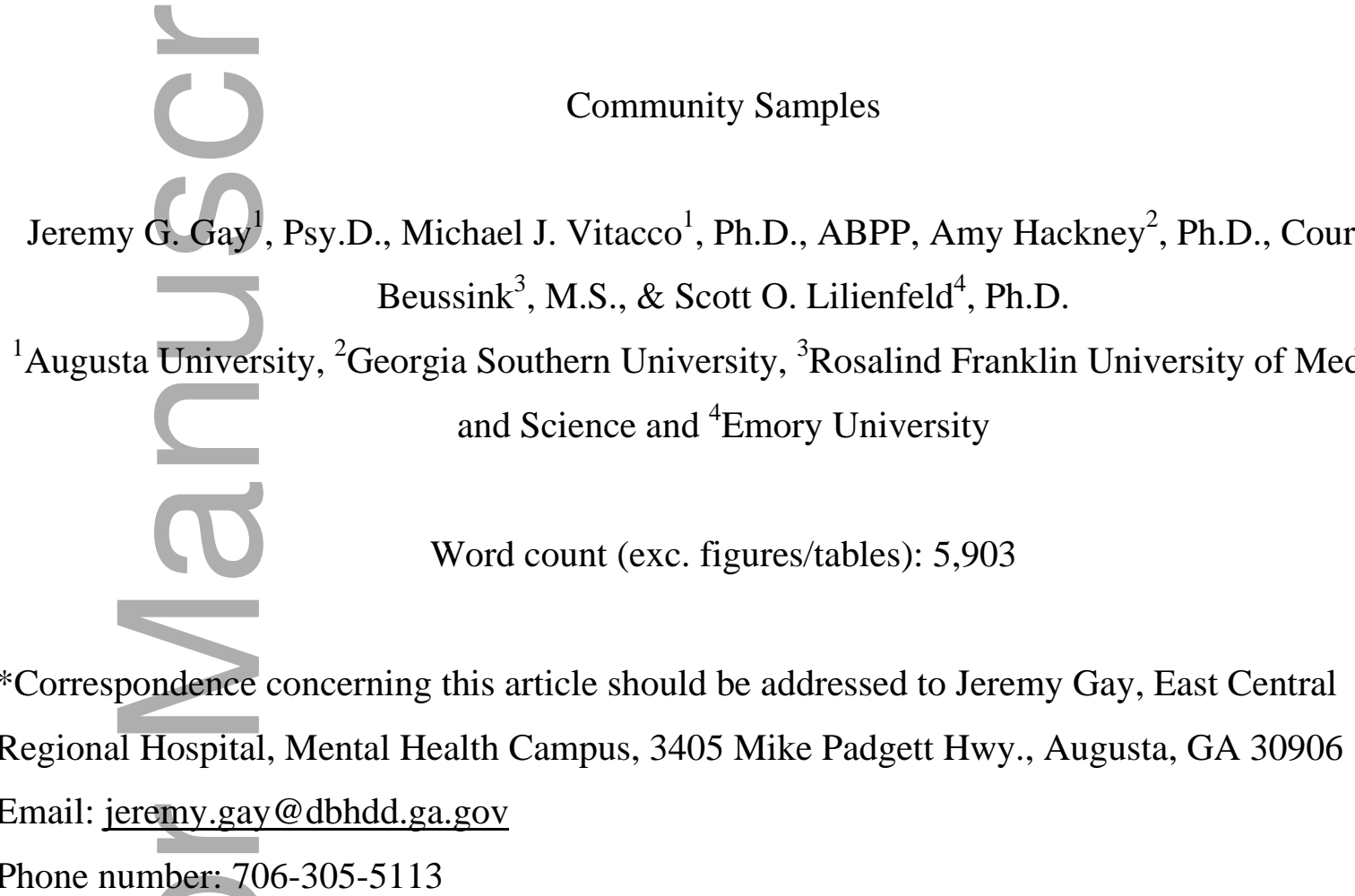

Phone number: 706-305-5113

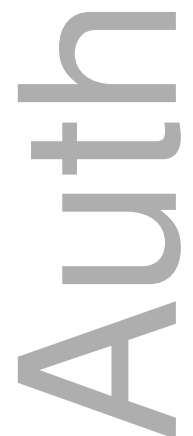

This is the author manuscript accepted for publication and has undergone full peer review but has not been through the copyediting, typesetting, pagination and proofreading process, which may lead to differences between this version and the Version of Record. Please cite this article as doi: $\underline{10.1111 / \text { lcrp.12128 }}$

This article is protected by copyright. All rights reserved 
Article Type: Article

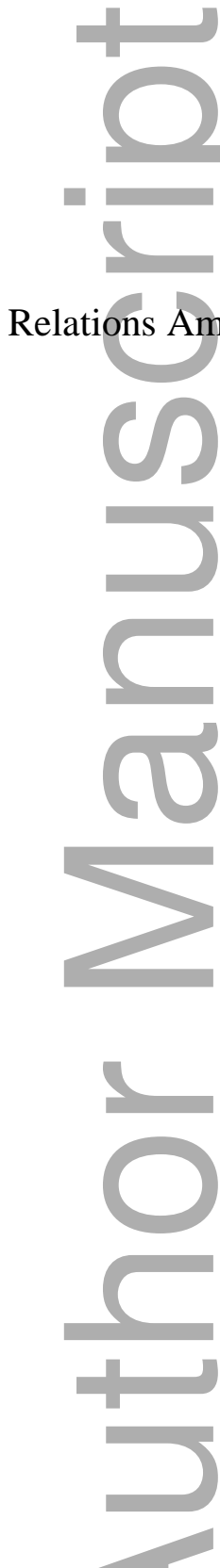

Community Samples

\begin{abstract}
Purpose. The nature of moral decision-making in those with pronounced psychopathic traits has been passionately debated, both in scientific literature and in the public policy arena. Research investigating the relationship between psychopathic traits and moral decision-making capacities has been largely inconclusive. However, recent research suggests individuals with elevated psychopathic traits may exhibit abnormal moral intuitions regarding the prevention of harm
\end{abstract}


(Harm) and promotion of fairness (Fairness). Although moral intuitions are widely assumed to be related to moral judgment, no research has simultaneously examined the relations among psychopathy, moral intuition, and moral judgment.

Methods. We hypothesized that psychopathic traits would not be directly related to moral judgment outcomes but would be indirectly related by way of Harm and Fairness moral intuitions. To test these hypotheses, 121 undergraduate students and 205 community residents, across two studies, completed measures of psychopathy, moral intuitions, and moral judgment.

Results. Higher psychopathy scores were associated with decreased concerns about preventing harm and promoting justice across both samples. Individuals higher in psychopathic traits did not evidence deficits in moral judgment.

Conclusions. Our findings indicate that, although individuals with elevated psychopathic traits may organize their sense of morality differently, they can accurately discern moral from immoral decisions.

Key words: psychopathy; moral judgment; moral intuitions; antisocial behavior

\section{Relations Among Psychopathy, Moral Competence, and Moral Intuitions in Student and Community Samples}

Psychopathy has long been considered a disorder with substantial moral implications. Prichard (1835) referred to psychopathy as "moral insanity," reflecting the idea that individuals with high levels of psychopathic traits are lacking in basic morality. Ellis (1890) labeled these individuals as "moral monsters" (p.17), and Cleckley (1941) described individuals with marked psychopathic traits as lacking a moral sense.

These classic clinical descriptions notwithstanding, the nature of the moral deficits ostensibly observed in individuals with elevated levels of psychopathy has been a point of contention. Two opposing views have emerged. The first view is largely cognitive in nature, and centers on the notion that individuals with high levels of psychopathic traits possess deficits in the capacity to differentiate right from wrong. Some proponents of this view have argued that individuals with elevated psychopathic traits should be considered eligible for the insanity defense given that they do not grasp the moral gravity of their often antisocial actions (Levy, 2008; Morse, 2008). The contrasting view, which is largely motivational in nature, is that 
individuals with high levels of psychopathy scores understand and are aware of moral issues that they engage in antisocial behaviors with the knowledge their conduct is ethically wrong (Erickson \& Vitacco, 2012; Vitacco, Erickson, \& Lishner, 2013).

Research on psychopathy and moral judgment has often yielded mixed results and, as a result, is challenging to interpret (Borg \&Sinnott-Armstrong, 2013). Because of the inconsistencies in the scientific literature, Marshall, Watts, and Lilienfeld (2016) conducted a meta-analysis to evaluate the relation between psychopathy and moral judgment. Drawing from 23 studies $(\mathrm{N}=4,376)$ that examined various measures of psychopathy, including self-report measures (e.g., PPI-R), and moral judgment tasks (e.g., Sacrificial Moral Dilemmas, Kohlbergian moral reasoning tasks), they detected small but statistically significant relations between psychopathy scores and commonly used measures of moral decision making $\left(\mathrm{r}_{\mathrm{w}}=.16\right)$ and moral reasoning $\left(\mathrm{r}_{\mathrm{w}}=.10\right)$. However, they did not find much evidence for "pronounced and overarching" moral deficits in conjunction with psychopathic traits, suggesting that reports of marked deficits may have been overstated, perhaps owing to publication biases (Marshall et al., 2016, p. 48). As such, the authors concluded, "Our results raise the distinct possibility that psychopathic individuals are more capable of understanding morality than has been traditionally assumed by laypersons, many mental health professionals, and some prominent psychopathy researchers and theorists. Our meta-analytic findings not only bear implications for our understanding of psychopathic individuals' immoral behavior, but may also raise questions concerning proposals from legal scholars (e.g., Levy, 2008) to excuse psychopathic individuals from criminal responsibility in light of their ostensibly deficient moral comprehension." (p. 48). Psychopathy and Moral Psychology

According to Kohlberg and colleagues, moral decision-making and behavior are byproducts of reasoning and deliberation (Kohlberg, Levine, \& Hewer, 1983, p. 69; see also Kohlberg, 1969). In other words, humans generally think about the consequences of an action before determining whether it constitutes a moral violation. According to this perspective, reasoning is the most important and dependable way to obtain moral knowledge (Haidt, 2012). In the context of psychopathy, rationalists (i.e., theorists who believe that reasoning is the optimal way to obtain moral knowledge) contend that individuals with elevated levels of psychopathic traits lack the capacity to make appropriate, morally-based decisions (Nichols, 2002). Despite the prevalence of this perspective in moral psychology, some scholars have proposed that 
individuals with high psychopathic traits possess the ability to discern the appropriate moral action required to differentiate right from wrong (Aharoni et al., 2012; Cima et al., 2010). From this perspective, individuals with high levels of psychopathic traits possess the capacity to rationally appraise the moral quality of an argument without feeling compelled to modulate their moral behavior (Nichols, 2002). Such evidence challenges the validity of a purely rationalist model of highly psychopathic individuals' morality.

Work by Haidt (2001) suggests that individuals are frequently unable to explain the processes by which they formulate moral decisions or judgments, often judging certain social constructs (e.g., cannibalism of a deceased human; cutting up one's old American flag and using it as a cleaning rag) as "wrong" without being able to articulate reasons why they are wrong, a curious phenomenon termed "moral dumbfounding." To this point, Haidt argued that moral reasoning is a skill humans acquired as a means to justify their moral decisions rather than viceversa. The Moral Foundations Model (Haidt, 2012; Haidt \& Graham, 2007) proposes five basic foundations of morality, namely (1) preventing harm to others (Harm), (2) preserving fairness, equal rights, and justice (Fairness), (3) practicing loyalty toward one's in-group relative to treatment towards outgroups (In-group/Loyalty), (4) respecting authority within hierarchical relationships (Authority), and (5) practicing purity or sanctity of body, mind, and soul (Purity/Sanctity). Research suggests that healthy adults organize their moral intuitions in this manner across cultural settings (Graham et al., 2011).

According to the Moral Foundations Model, moral intuitions arise automatically before moral judgments are made, and people subsequently justify their intuitions by way of moral reasoning. As such, humans are theoretically predisposed to affectively experience moral intuitions, which can later be modified by internal (e.g., personality traits) and external (e.g., cultural) factors (Haidt \& Joseph, 2004). From this standpoint, people first make moral decisions based on their initial gut reactions (emotion/affect) and subsequently justify these reactions through a process of reasoning (cognition).

Research using forensic (Aharoni, Antonenko, \& Kiehl, 2011) and community (Glenn, Iyer, Graham, Koleva, \& Haidt, 2009) samples has found that individuals higher in psychopathy were less likely to endorse a desire to prevent harm and promote fairness than were individuals lower in psychopathy; these studies yielded no other significant differences in moral intuitions as a function of psychopathy. These moral intuitions are thought to be instrumental in guiding 
moral judgment (Crone \& Laham, 2015; Haidt, 2001; Koleva, Selterman, Iyer, Ditto, \& Graham, 2013) and ultimately behavior. However, neither of the aforementioned studies (Aharoni et al., 2011; Glenn et al., 2009) explicitly assessed moral judgment, and both instead relied on moral intuitions. Although moral intuitions have been hypothesized to be directly related to explicit moral judgment (Haidt, 2001), little research has examined this model empirically. By acquiring a nuanced understanding of moral intuitions in relation to psychopathic traits and moral judgment, researchers can better understand the pathological components of moral decision making in individuals with elevated psychopathy scores.

\section{Current Studies}

The purpose of the two studies reported here was to examine the relations between psychopathy and both moral intuitions and moral judgment. As observed earlier, research regarding psychopathy's role in moral judgment has been largely inconclusive. This lack of clarity is problematic, particularly in the legal arena, as moral deficits may influence individuals' legal responsibility for their actions (Morse, 2008; see also Litton, 2007). Of the 46 U.S. states that currently employ the insanity defense, 40 allow for consideration of both moral and legal wrongfulness (Packer, 2009). To that end, we proposed and tested two hypotheses.

First, consistent with prior research, we hypothesized that the moral intuitions to prevent harm to others and preserve fairness would be significantly lower in participants with elevated psychopathy scores. As psychopathy is marked largely by callousness and manipulativeness (Berg, Hecht, Latzman, \& Lilienfeld, 2015; Hare \& Neumann, 2008), these traits should relate to moral intuitions (see Aharoni et al., 2011; Glenn et al., 2009; Haidt, 2012). Second, we hypothesized that psychopathy would not be directly related to moral judgment deficits ${ }^{1}$ but would be indirectly related to moral judgment deficits by way of moral intuitions.

Regarding this first possibility, we tested the idea that although individuals with high levels of psychopathic traits organize their sense of "morality" in terms of moral intuitions (e.g.,

${ }^{1}$ Although a recent meta-analysis (Marshall, Watts, \& Lilienfeld, 2016) found a significant relationship between psychopathic traits and moral judgment deficits, the effect sizes were small, suggesting that although these relationships may be statistically significant, they may lack practical significance (see p. 3 for further discussion). 
decreased concern of preventing harm to others or preserving fairness in society), they would be able to distinguish moral from immoral decisions. This viewpoint is consistent with research (Aharoni et al., 2012; Cima et al, 2010), including a recent meta-analysis (Marshall et al., 2016), as well as Haidt's hypothesis that individuals with high levels of psychopathy reason "quite well," but, due to their "lack of moral emotions," learn what to do and say to fulfill their desired outcomes (Haidt, 2013, p. 73). In addition, based on research (Aharoni et al., 2011; Glenn et al., 2009), we hypothesized that intuitions to prevent harm to others and preserve fairness would mediate the relationship between psychopathic traits and moral judgment. Recent research (Koleva et al., 2013; Crone \& Laham, 2015) suggests that moral intuitions predict moral judgments. However, extant research has not examined these relationships in the context of psychopathy. To test this alternative hypothesis, we conducted a series of Preacher and Hayes' (2004) mediation models with psychopathy as the predictor variable, the moral intuitions of Harm and Fairness as mediators, and moral judgment as the outcome variable.

\section{Study One: Undergraduate Sample}

\section{Method}

Inclusion Criteria for Study and Analyses

Inclusion criteria for the study included being age 18 or older. Inclusion criteria for the analyses included completing and adequately attending to all the administered measures. Attention was measured by including one "catch question," written by one of the study's authors, in each measure. Catch questions (e.g., "If you are paying attention, select False for this item") were composed to match the format and response options of each survey's questions. Catch questions were included due to the relatively high levels of inattention found in some online samples (e.g., Fleischer, Mead, \& Huang, 2015). Participants who did not finish all administered measures $(\mathrm{N}=9)$ or answer all three catch questions correctly $(\mathrm{N}=37)$ were excluded from the analyses, leaving a final sample of 121 undergraduates. Excluded participants did not differ from included participants in terms of age, $\mathrm{F}(1,156)=.33, \mathrm{p}=.57$. However, there were significant differences between included and excluded participants in terms of race, $X^{2}(9, N=158)=28.30$, $\mathrm{p}<.001$ and gender, $\mathrm{X}^{2}(2, \mathrm{~N}=158)=5.96, \mathrm{p}=.05$. This racial difference was due in part to excluding two Native American and three racially unidentified participants, as no Native American or racially unidentified participants were included in the final sample. The gender difference was due to including significantly more female participants than we excluded (we 
included 85 female participants and excluded 20).

Participants

Participants were all enrolled in a regional southeast public university in the United States. Thirty-six were male (30\%) and 85 were female (70\%). Of the sample, 80 participants identified as Caucasian (66\%), 24 as African American (20\%), six as Hispanic (5\%), one as Asian (1\%), and one as American Indian/Alaskan Native (1\%). Nine participants identified as Multiracial $(7 \%)$. The mean age of the sample was almost 20 years of age $(\mathrm{M}=19.62 ; \mathrm{SD}=$ 2.46). Participants were recruited through the Psychology Department's web-based research participation pool. They completed the study as a requirement for an undergraduate class or in exchange for extra credit. This study was approved by the university's Institutional Review Board (IRB).

Procedure

Participants independently completed a series of internet-based measures via Qualtrics software. A web link to the survey was included through the web-based research participation pool. The order of questionnaire administration was randomized. Participants received an introduction explaining that the purpose of the study was to assess the relation between personality and decision making.

Measures

Psychopathic Personality Inventory - Revised - Short Form. Psychopathic traits were measured using the Psychopathic Personality Inventory-Revised-Short Form (PPI-R-SF; Lilienfeld \& Hess, 2001). The PPI-R-SF was chosen because it has been well validated in undergraduate and community samples (Lilienfeld \& Hess, 2001; Lilienfeld, Latzman, Watts, Smith, \& Dutton, 2014). The PPI-R-SF is a 56-item, self-report measure of psychopathic traits and items are answered on a 4 -point scale $(1=$ false, $2=$ mostly false, $3=$ mostly true, $4=$ true $)$. At least in nonclinical samples, the PPI-R-SF exhibits the same higher-order three factor structure (i.e., Fearless Dominance, Self-Centered Impulsivity, and Coldheartedness) and uses the same eight factor-analytically developed content scales from the full Psychopathic Personality Inventory-Revised. The Fearless Dominance factor is composed of the Social Influence, Fearlessness, and Stress Immunity Scales, whereas the Self-Centered Impulsivity Factor is composed of the Machiavellian Egocentricity, Rebellious Nonconformity, Blame 
Externalization, and Carefree Nonplanfulness scales (Lilienfeld \& Widows, 2005). The Fearless Dominance factor reflects low levels of tension and anxiety and high levels of physical risktaking and interpersonal dominance; the Self-Centered Impulsivity factor reflects high levels of impulsivity, blame externalization, and self-centeredness; and the Coldheartedness factor reflects high levels of callousness and an absence of guilt (Lilienfeld \& Widows, 2005). The PPI-R-SF has correlated $\mathrm{r}=.90$ or above with the full form in several undergraduate samples (Lilienfeld \& Hess, 2001). The internal consistency of the PPI-R-SF total score in our undergraduate sample was .86. The internal consistencies of the three PPI factor scores ranged from .67 (Coldheartedness Factor) to .84 (Self-Centered Impulsivity).

The overall levels of psychopathy found in our undergraduate sample were comparable to those from the normative data extracted from the shorter version of the PPI-R normative sample, which used a combined undergraduate/community sample (Lilienfeld \& Widows, 2005). Nevertheless, as the PPI-R was designed to assess psychopathy dimensionally (see Marcus, John, \& Edens, 2004, for evidence that PPI-assessed psychopathy is dimensional rather than taxonic), it does not provide recommended cutoff scores to distinguish "psychopaths" from "nonpsychopaths." The practice of treating psychopathy dimensionally and not categorically is consistent with the prevalent view and existing literature on the PPI, Psychopathy-ChecklistRevised, and other well-validated psychopathy measures (e.g., Edens, Lilienfeld, Marcus, \& Poythress, 2006; Marcus, John, \& Edens, 2004; Skeem, Polaschek, Patrick, \& Lilienfeld, 2011) that psychopathy is a continuous (dimensional) and non-taxonic entity. As such, we examined psychopathy scores using continuous scores ${ }^{2}$.

Moral Foundations Questionnaire. Moral intuitions were measured using the Moral Foundations Questionnaire (MFQ; Graham et al., 2011), a 30-item, self-report measure of moral

\footnotetext{
${ }^{2}$ Although a number of studies have analyzed psychopathy as a categorical variable, in some cases using median splits, this practice is inconsistent with evidence, reviewed here, that psychopathy is a non-taxonic, continuous variable. Furthermore, the dichotomization of continuous variables almost always results in decreased statistical power and is therefore inadvisable (MacCallum, Zhang, Preacher, \& Rucker, 2002).
} 
intuitions and items are answered on a 5-point scale ( $1=$ Strongly Disagree, $5=$ Strongly Agree $)$. Participants evaluate the extent to which each item is "relevant to their thinking" when making moral decisions and indicated their agreement or disagreement with questions such as "one of the worst things a person could do is hurt a defenseless animal." The MFQ is composed of five moral foundations (6 items per foundation): Harm (i.e., ability to feel the pain of others), Fairness (i.e., reciprocal altruism or concerns about justice, rights, and autonomy), Ingroup/Loyalty (i.e., patriotism and self-sacrifice for group), Authority (i.e., leadership and followership), and Purity/Sanctity (i.e., striving to live a noble life). Higher MFQ scale scores represent higher preference for the specific moral intuition assessed and none of the scales are reversed scored. The internal consistencies of the MFQ scales have ranged from .65-.84 in previous research (Graham et al., 2011). The internal consistencies of the 5 MFQ Factor scores ranged from to .56 (Authority) to .70 (Purity/Sanctity) in our undergraduate sample.

Moral Competence Test. Moral judgment was measured using the Moral Competence Test (MCT; Lind, 1978 \& Lind, 2014). The MCT (formerly known as the Moral Judgment Test) is a 28-item, self-report measure that is answered on a 9-point scale (-4 = I completely reject, +4 $=\mathrm{I}$ completely accept). Participants read a vignette of two different moral scenarios and rate the acceptability of each proceeding moral argument (e.g., do you accept or reject the following arguments in favor of the two workers' behavior? Suppose someone argued they were right because they did not cause much damage to the company). We used the $\mathrm{C}$-index, which reflects a person's ability to judge arguments according to their moral quality. The C-index is calculated based on an analysis of the total pattern of responses, yielding an overall score of one's "moral competence" (Lind, 2014). The C-score is classified according to its value: low, 1-9; medium, 10-29; high, 30-49; and very high, >50 points.

The MCT has been well-validated in many different cultures and languages (Lind, 2005). For example, the C-Index is positively associated with democratic attitudes and negatively associated with dogmatic attitudes, external locus of control, and intolerance for ambiguity (Lind, Hartmann, \& Wakenhut, 1985). In addition, the C-Index is positively associated with other measures of moral judgment (Ishida, 2006). The internal consistency of the C-Index has been reported to be as high as .90 (Lerkiatbundit, Utaipan, Laohawiriyanon, \& Teo, 2006). The 
internal consistency of the MCT C-Index was .71 in our undergraduate sample ${ }^{3}$. Although the overall moral competence (based on C-Index scores) of the participants in this study was diverse, the majority of the participants' moral competence scores fell in the low (41\%) and medium (44\%) ranges. Eight percent of the participants' scores fell in the high range and seven percent fell in the very high range.

Demographics. Participants completed a demographic questionnaire concerning their gender, race, ethnicity, religion, years of education, and age.

\section{Descriptive Statistics}

Results

None of the distributions for the analyzed variables was markedly skewed. Descriptive statistics, including means and standard deviations, were calculated for each measure [Psychopathic Personality Inventory - Revised - Short Form (PPI-R-SF); Moral Competence Test (MCT); Moral Foundations Questionnaire (MFQ)] and detailed descriptive statistics for each measure, including scales and factor scores, are reported in Table 1.

Relationships Among Psychopathy, Moral Intuitions, and Moral Judgment

Zero-order correlations, reported in Table 2, revealed no significant relationships between Psychopathic Personality Inventory-Revised-Short Form (PPI-R-SF) total, PPI-R-SF Fearless Dominance Factor, PPI-R-SF Self-Centered Impulsivity Factor, or PPI-R-SF Coldheartedness Factor scores, on the one hand, and the Moral Competence Test (MCT) C-Index scores on the other. With regard to moral intuitions, however, the moral intuitions of Harm, Fairness, and Purity/Sanctity were negatively correlated with the PPI-R-SF total and PPI-R-SF Coldheartedness Factor scores. The PPI-R-SF Self-Centered Impulsivity Factor was also negatively associated with Fairness and Purity/Sanctity, but not Harm. The PPI-R-SF Fearless Dominance factor was positively associated with the moral intuition of In-group/Loyalty. No other significant associations were found between the PPI-R-SF total or factor scores and moral intuitions.

\footnotetext{
${ }^{3}$ Lind (2014) cautioned against examining the internal consistency of the C-Index because the MCT regards consistent response patterns as a sign of a person's moral judgment competence and not as an inherent attribute of the test.
} 
The Relation between both Psychopathy and Moral Intuitions on Moral Judgment

To examine the potential distinctive contributions of psychopathy dimensions above and beyond each other for statistically predicting moral judgment, a simultaneous multiple regression was conducted. These analyses were exploratory, as little research has examined the differential contributions of psychopathy factors in the context of moral intuitions or moral judgment. Specifically, the three PPI-R-SF factors were entered simultaneously to ascertain if psychopathic traits in aggregate predict Moral Competence Test (MCT) C-Index scores. The model was not supported, $\mathrm{R}^{2}=.01, \mathrm{~F}(3,117)=.47, \mathrm{p}=.70$, suggesting that psychopathic traits did not predict actual moral judgments ${ }^{4}$. Next, to examine the distinctive contributions of moral intuitions for statistically predicting moral judgment, a simultaneous multiple regression was conducted. Specifically, the five Moral Foundations Questionnaire scales were entered simultaneously to ascertain if moral intuitions statistically predict Moral Competence Test (MCT) C-Index scores. The model was again not supported, $\mathrm{R}^{2}=.02, \mathrm{~F}(5,115)=.56, \mathrm{p}=.73$, suggesting moral intuitions did not predict actual moral judgments.

Mediation Analyses

To test the proposed mediation model, a series of Preacher and Hayes' (2004) mediation analyses were performed with PPI-R-SF total as the predictor variable, each individual Moral Foundations Questionnaire scale as the posited mediator variable, and Moral Competence Test (MCT) C-Index score as the outcome variable. Bias-corrected bootstrapping procedures were used $(\mathrm{N}=5000)$ to generate $95 \%$ confidence intervals (Preacher \& Hayes, 2004). This analysis was chosen because neither the predictor and mediator nor the mediator and outcome variables is required to be significantly related to one another to conduct the analysis. Overall, none of the proposed mediation models was supported, as no significant direct or indirect effects were found (see Table 3).

Study One Discussion

\footnotetext{
${ }^{4}$ In a subsidiary analysis, we conducted a multiple analysis of variance (MANOVA) with Lind's proposed C-Index moral competence categorizations (low, medium, high, very high) as the independent variable and psychopathy factor scores as the outcome variables. Moral competence categorizations were again not significantly associated with psychopathy scores.
} 
These results suggest that psychopathy is not significantly associated with deficits in moral judgment in an undergraduate sample; in addition, we detected no significant indirect effects, as moral intuitions did not mediate the relationship between psychopathy and moral judgment. However, consistent with prior research (e.g., Aharoni et al., 2011; Glenn et al., 2009), psychopathy was negatively related to the moral intuitions of Harm, Fairness, and Purity. These findings suggest that, although individuals with high levels of psychopathy may exhibit decreased concerns about harm prevention and societal fairness, they are largely capable, at least in principle, of adequate moral decision-making. To examine a greater range of psychopathic traits in a more diverse and larger sample, we aimed to conceptually replicate our findings using a community sample. ${ }^{5}$

Study Two: Community Sample

Method

Inclusion Criteria for Study and Analyses

The inclusion criteria for this study were identical to those of Study One. Participants who did not finish all administered measures $(\mathrm{N}=23)$ and answer all three catch questions correctly $(\mathrm{N}=37)$ were excluded from the analyses. Excluded $(\mathrm{M}=31.57 ; \mathrm{SD}=2.35)$ participants in this sample were significantly younger than included participants $(M=41.82$; SD $=1.00 ; \mathrm{F}(1,240)=16.16, \mathrm{p}<.001)$; this difference was very large in magnitude (Cohen's $\mathrm{d}=$ 5.48). Additionally, there was a significant racial difference between chosen and excluded participants, $\mathrm{X}^{2}(8, \mathrm{~N}=244)=43.85, \mathrm{p}<.001$. This racial difference was due in part to including significantly more African American (excluded 5 and included 14), Caucasian (excluded 19 and included 172), Asian (excluded 4 and included 8), and Multiracial (excluded 1 and included 8) participants than excluded. No significant gender differences emerged between included and excluded participants, $\mathrm{X}^{2}(2, \mathrm{~N}=242)=3.14, \mathrm{p}=.21$.

Participants

Participants were recruited from Amazon Mechanical Turk (MTurk) and paid 55 cents

${ }^{5}$ A series of independent samples t-test analyses revealed that the undergraduate sample obtained significantly higher psychopathy scores than the community sample across psychopathy factors with the exception of Coldheartedness, which did not differ significantly between groups. 
after answering the catch questions correctly and completing all measures. The final sample consisted of 205 community residents from across the United States. Of these, 76 were male $(37 \%)$ and 128 were female (62\%); one participant identified as transgender. One hundred and seventy-two participants identified as Caucasian (85\%), 14 as African American (7\%), eight as Asian (4\%), one as American Indian/Alaskan Native, and one as Hispanic. Eight participants identified as Multiracial (4\%) and one participant declined to respond. The mean age was almost 42 years of age $(M=41.82 ; \mathrm{SD}=14.97)$.

Procedure

A brief description regarding the questionnaire, including its length and incentive value, was posted on the MTurk website, and MTurk workers signed up voluntarily to complete the survey at the time and location of their choosing. Participants then received an introduction, which informed them that the purpose of the study was to examine the relationship between personality and decision making. The order of questionnaire administration was again randomized. The same measures included in Study One were included in Study Two (see Study One measures section). The internal consistency of the Psychopathic Personality InventoryRevised-Short Form (PPI-R-SF) total score in the community sample was again.86. The internal consistencies of the three PPI Factor scores ranged from .78 (Coldheartedness) to .86 (SelfCentered Impulsivity) in our community sample. The internal consistencies of the 5 Moral Foundations Questionnaire (MFQ) factor scores ranged from .63 (Fairness) to .87 (Purity/Sanctity). The internal consistency of the Moral Competence Test (MCT) C-Index was .67. As in Study One, participants' overall moral competence scores were diverse; the majority of the participants' moral competence scores fell in the low (46\%) and medium (41\%) ranges. Eight percent of the participants' scores fell in the high range and 5 percent fell in the very high range. The participants' overall level of moral competence did not differ significantly between Studies One and Two, $X^{2}(3, N=326)=1.66, p=.64$.

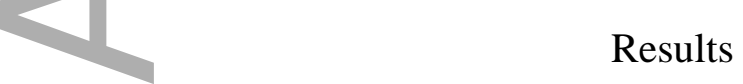

Descriptive Statistics

None of the distributions for the analyzed variables was markedly skewed. Descriptive statistics for these measures, including means, standard deviations, and ranges are reported in 
Table 1.

Relationships Among Psychopathy, Moral Intuitions, and Moral Judgment

Zero-order correlations, displayed in Table 4, again revealed no significant relationships between PPI-R-SF total, PPI-R-SF Fearless Dominance Factor, PPI-R-SF Self-Centered Impulsivity Factor, or PPI-R-SF Coldheartedness Factor scores, on the one hand, and Moral Competence Test (MCT) C-Index scores, on the other. ${ }^{6}$ With regard to moral intuitions, Harm and Fairness were negatively associated with the PPI-R-SF total, PPI-R-SF Fearless Dominance Factor, and PPI-R-SF Coldheartedness Factor scores. Similarly, Harm was negatively associated with PPI-R-SF Self-Centered Impulsivity Factor scores. Purity/Sanctity was also negatively associated with PPI-R-SF total and PPI-R-SF Self-Centered Impulsivity Factor scores. Authority was negatively associated with PPI-R-SF total and PPI-R-SF Self Centered Impulsivity Factor scores. No other significant associations emerged between PPI-R-SF total and factor scores and other moral intuitions.

The Relation between Both Psychopathy and Moral Intuitions and Moral Judgment

To examine the distinctive contributions of psychopathy dimensions above and beyond each other for statistically predicting moral judgment, we again performed a simultaneous multiple regression. These analyses were again exploratory, as little research has examined psychopathy factors in the context of moral judgment. Specifically, the three PPI-R-SF factors were simultaneously entered to assess if psychopathic traits predict Moral Competence Test CIndex scores. The model was again not supported, $\mathrm{R}^{2}=.03, \mathrm{~F}(3,202)=1.86, \mathrm{p}=.14$, indicating that psychopathic traits did not predict moral judgments ${ }^{7}$. Next, to examine the distinctive

\footnotetext{
${ }^{6}$ As in Study One, there was a small but significant negative correlation between the PPI-R-SF Carefree Nonplanfulness subscale and Moral Competence Test (MCT) C-Index scores, r(204)= $-.19, \mathrm{p}=.01$. There were no significant relations between the other PPI-R-SF subscales and MCT C-Index scores.

${ }^{7}$ A MANOVA was again performed with Lind's proposed Moral Competence Test (MCT) CIndex moral competence categorizations (low, medium, high, very high) as the independent
} 
contributions of moral intuitions for statistically predicting moral judgment, a simultaneous multiple regression was conducted. Specifically, the five Moral Foundations Questionnaire (MFQ) scales were entered simultaneously to ascertain whether moral intuitions predict Moral Competence Test (MCT) C-Index scores. In contrast to the findings of Study One, the model was supported, $\mathrm{R}^{2}=.06, \mathrm{~F}(5,200)=2.34, \mathrm{p}=.04$. However, none of the MFQ scales was a significant predictor in the overall model.

Mediation Analyses

To test the proposed mediation model, a series of Preacher and Hayes' (2004) mediation analyses were performed with PPI-R-SF total as the predictor variable, each individual Moral Foundations Questionnaire scale as the mediator variable, and Moral Competence Test (MCT) C-Index as the outcome variable. Bias-corrected bootstrapping procedures were used $(\mathrm{N}=5000)$ to generate $95 \%$ confidence intervals (Preacher \& Hayes, 2004). As in Study One, none of the proposed mediation models was supported, as no significant direct or indirect effects were found (see Table 5).

Study Two Discussion

As in Study One, the results suggest that psychopathy is not significantly associated with global deficits in moral judgment. In addition, no significant indirect effects emerged, as moral intuitions did not significantly mediate the relation between psychopathy and moral judgment. Consistent with Study One and prior research (e.g., Aharoni et al., 2011; Glenn et al., 2009), psychopathy was negatively related to the moral intuitions of Harm, Fairness, and Purity. In contrast to Study One, psychopathy was negatively related to the Authority moral intuition, suggesting that individuals with high psychopathy scores tend to believe that people should not respect and follow traditional authority figures. Counter to Study One's findings, moral intuitions were predictive of moral judgment outcomes in the community sample. However, no specific individual moral intuition was a predictor in the overall model, suggesting that this result was attributable to their shared rather than their unique variance.

General Discussion

variable and psychopathy factor scores as the outcome variables. Moral competence categorizations were again not significantly associated with psychopathy scores. 
This study is among the first to examine the relations among psychopathy, moral intuition, and moral judgment (see also Aharoni et al., 2011; Glenn et al., 2009). In considering the relation between psychopathy and moral judgment, there have traditionally been two competing viewpoints, the first primarily cognitive and the second primarily motivational. According to the first perspective, individuals with marked features of psychopathy lack both the basic capacity to understand right from wrong and the ability to perceive the immorality of their actions. The second perspective holds that psychopathic individuals can distinguish right from wrong, but nonetheless choose to engage in immoral behavior because of the rewards it brings. The results of this study are a modest but useful step forward in disentangling the conflicting results from previous research.

The Relationship Between Psychopathy and Moral Intuitions

Consistent with prior research (Aharoni et al., 2011; Glenn et al., 2009), we found a negative relationship between psychopathy and the moral intuitions to prevent harm to others and promote fairness in society across both samples. In other words, as levels of psychopathic traits increase, concerns about preventing harm and promoting justice in society decreases. However, this pattern did not hold across all psychopathy subdimensions. For example, SelfCentered Impulsivity was not significantly related to Fairness concerns across both samples and, in the undergraduate sample, Fearless Dominance was not related to the moral intuitions of Harm and Fairness. Overall, these results suggest individuals with higher psychopathy scores do not value societal fairness and harm prevention. These findings are broadly consistent with theoretical and empirical work suggesting individuals higher in psychopathy manifest deficiencies in their concerns about the welfare of others (Blair, 2007), perhaps stemming from a decreased ability to empathize with others (Jonason \& Kroll, 2015; Khvatskaya \& Lenzenweger, 2016). With respect to psychopathy and moral intuitions, psychopathy was negatively related to the moral intuition to practice purity or sanctity of body, mind, and soul. Given their tendency to make insincere commitments to personal goals, interpersonal relationships, and societal principles, it is perhaps not surprising that individuals higher in psychopathy exhibited decreased concerns about purity (Hare \& Neumann, 2008; Riopka, Coupland, \& Olver, 2015).

We also examined the relations between the three major PPI factors of psychopathy (i.e., Fearless Dominance, Self-Centered Impulsivity, and Coldheartedness), on the one hand, and moral intuitions, on the other. Although we advanced no predictions regarding the correlates of 
specific psychopathy factors, such analyses shed potentially useful light on the fine-grained predictors of thinking about moral problems. Overall, Fearless Dominance was negatively associated with concerns regarding the prevention of harm to others and the promotion of fairness in our community sample, with a similar, albeit non-significant trend in our undergraduate sample. Similarly, we found that the Self-Centered Impulsivity factor was negatively related to harm prevention, fairness concerns, purity concerns, and respect for authority in both samples. This finding is understandable given that Self-Centered Impulsivity is characterized by blame externalization and self-centeredness in addition to impulsivity. People who are impulsiye and excessively preoccupied with fulfilling their own wants, needs, and desires are unlikely to hold egalitarian values, concern themselves with societal justice, or seek to honor authority figures. Lastly, we found the Coldheartedness factor was negatively related to harm prevention, fairness concerns, and purity in both samples. Again, these findings are understandable given that Coldheartedness is characterized by a lack of guilt, tender social emotions, and regard for other's feelings. As such, individuals who have little regard for the well-being of others, combined with a lack of guilt about their lack of concern, would have scant regard for the concerns of others, let alone broader social justice concerns. Nevertheless, these linkages are provisional and warrant replication in independent samples, especially those characterized by more extreme levels of psychopathy. The Relationship Between Psychopathy, Moral Intuitions, and Moral Judgment

Across both samples, psychopathy dimensions were not significantly related to impaired moral judgment. Similarly, with the exception of Carefree Nonplanfulness, PPI-R-SF subscales were not significantly related to impaired moral judgment in either sample. The replicated exception for Carefree Nonplanfulness was not predicted, but it raises the intriguing possibility that this subcomponent of psychopathy impedes moral decision-making, perhaps because it is a proxy of insouciance regarding ethical matters; further investigation of this possibility is worth pursuing.

Our findings are broadly consistent with previous literature (Aharoni et al., 2012; Cima et al., 2010) and suggest that, despite abnormalities in behavior, emotion, and empathy, individuals with higher levels of psychopathic traits - with the potential exception of Carefree Nonplanfulness - display few or no marked impairments in moral judgment per se. Given their apparently intact moral judgment capabilities, individuals with elevated psychopathy features 
appear largely aware of the moral wrongfulness of their actions. However, due to their increased motivation to obtain rewards (Buckholtz et al., 2010) coupled with lower empathy (Blair, Jones, Clark, \& Smith, 1997), they may not care that their actions are morally impermissible.

Some influential legal scholars (e.g., Morse, 2008) have argued that individuals with high levels of psychopathy are lacking in important domains of moral knowledge. Specifically, they have contended that such individuals may recognize that their behaviors are "wrong," but fail to appreciate the profound moral gravity of their actions. Our findings cannot speak directly to this interesting possibility. Nevertheless, they appear to be inconsistent with the view that individuals with relatively high levels of psychopathy are "morally illiterate," that is, lacking in basic moral understanding. As such, it may be difficult to justify psychopathy as a "mental disease or defect" or to argue that most or all individuals with elevated levels of psychopathy "lack the ability to understanding moral wrongfulness" using the insanity test used in most U.S. jurisdictions (M’Naughten Rule, 1843; Model Penal Code $\S 4.01(1), 1962)$. Our findings are consistent with those of Aharoni and colleagues (2012), who concluded "there is insufficient evidence to support insanity defenses based simply on the inability of these individuals to understand moral wrongfulness" (p. 492) and Vitacco and colleagues (2013), who stated that "despite the involvement of brain areas and a long history of descriptions of emotional deficits associated with psychopathy, these deficits should not parlay into a change of current insanity standards that could hold high-psychopathy individuals criminally nonresponsible" (p. 424). Again, however, it will be important to conceptually replicate our findings in samples with more extreme levels of psychopathy, as it is possible that certain moral reasoning deficits emerge only when psychopathy becomes severe.

Although moral intuitions are thought to relate to a person's moral judgment, few studies have examined this assumption. We sought to remedy this omission by examining the relationship between moral intuition and moral judgment. In our community sample, we found a small but statistically significant positive relationship between the Fairness moral intuition and moral judgment and a small but statistically significant negative relationship between the Ingroup/Loyalty moral intuition and moral judgment. A similar trend emerged in our undergraduate sample. These results suggest that loyalty towards in-groups relates to poorer moral judgment. This finding is interpretable in light of research that participants tend to exhibit decreased empathetic responding when they perceive a person to be part of their out-group 
(Cikara, Bruneau, \& Saxe, 2011) and to broader literature on out-group biases as precursors to prejudice (Fiske, 2002).

Limitations and Future Directions

Although this study is among the first to simultaneously examine the relationships among psychopathy, moral intuitions, and moral judgment, several methodological limitations are worth noting. First, neither study relied on a clinical or forensic sample. Although this limitation could also be considered a strength in some respects (e.g., it may have allowed us to better unconfound psychopathy from criminality, thereby allowing us to examine the distinctive contribution of psychopathy in non-criminal, non-pathological individuals), this approach may have precluded us from obtaining the higher ranges of psychopathy scores seen in clinical and forensic samples. Even in studies using such samples, however, it will be important to control for broader antisocial and criminal deviance to ascertain the distinctive contribution of psychopathy, if any, above and beyond such deviance. Second, future research should examine the validity of the Moral Competence Test in populations with higher levels of psychopathic traits (e.g., criminal samples). Given the variety of moral judgment scales and the inconsistencies in the literature, greater standardization and operationalization would allow for a better understanding of the relation between psychopathy and specific moral judgments. This recommendation is particularly important to consider given that findings in this literature may hinge crucially on the type of moral judgment task administered (see also Palmer, 2003).

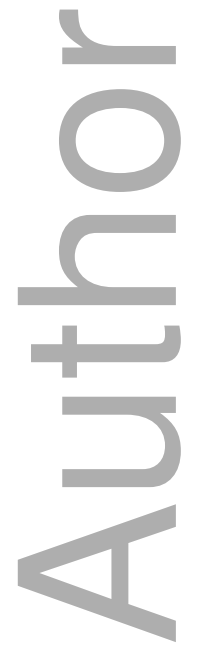




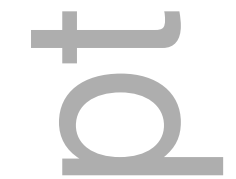

\section{References}

Aharoni, E., Antonenko, O., \& Kiehl, K. A. (2011). Disparities in the moral intuitions of criminal offenders: The role of psychopathy. Journal of Research in Personality, 45, 322327. doi:10.1016/j.jrp.2011.02.005

Aharoni, E., Sinnott-Armstrong, W., \& Kiehl, K. A. (2012). Can psychopathic offenders discern moral wrongs? A new look at the moral/conventional distinction. Journal of Abnormal Psychology, 121, 484-497. doi:10.1037/a0024796

Berg, J. M., Hecht, L. K., Latzman, R. D., \& Lilienfeld, S. O. (2015). Examining the correlates of the coldheartedness factor of the Psychopathic Personality Inventory-Revised. Psychological Assessment, 27, 1494-1499. doi:10.1037/pas0000129

Blair, R. J. R. (2007). The amygdala and ventromedial prefrontal cortex in morality and psychopathy. Trends in Cognitive Sciences, 11, 387-392. doi:10.1016/j.tics.2007.07.003

Blair, R. J. R., Jones, L., Clark, F., \& Smith, M. (1997). The psychopathic individual: A lack of responsiveness to distress cues? Psychophysiology, 34, 192-198. doi:10.1111/j.14698986.1997.tb02131.x

Borg, J. S., \& Sinnott-Armstrong, W. (2013). Do psychopaths make moral judgments? In K. Kiehl and W. Sinnott-Armstrong (Eds.), Handbook on psychopathy and law (pp. 107128). New York, New York: Oxford University Press.

Buckholtz, J. W., Treadway, M. T., Cowan, R. L., Woodward, N. D., Benning, S. D., Li, R., ... Zald, D. H. (2010). Mesolimbic dopamine reward system hypersensitivity in individuals with psychopathic traits. Nature Neuroscience, 13, 419-421. doi:10.1038/nn.2510

Cikara, M., Bruneau, E. G., \& Saxe, R. R. (2011). Us and them: Intergroup failures in empathy. Current Directions in Psychological Science, 20, 149-153. doi:10.1177/0963721411408713

Cima, M., Tonnaer, F., \& Hauser, M. D. (2010). Psychopaths know right from wrong but don't care. Social Cognitive \& Affective Neuroscience, 5, 59-67. doi:10.1093/scan/nsp051 
Cleckley, H. M. (1941). The mask of sanity. St. Louis, MO: Mosby.

Crone, D. L., \& Laham, S. M. (2015). Multiple moral foundations predict responses to sacrificial dilemmas. Personality and Individual Differences, 85, 60-65. doi:10.1016/j.paid.2015.04.041

Edens, J. F., Lilienfeld, S. O., Marcus, D. K., \& Poythress, N. J. (2006). Psychopathic, not psychopath: taxometric evidence for the dimensional structure of psychopathy. Journal of Abnormal Psychology, (1), 131. doi: 10.1037/0021-843X.115.1.131

Ellis, H. (1890). The Criminal. New York, NY: Scribner \& Welford.

Erickson, S. K., \& Vitacco, M. J. (2012). Punishment and predators. Psychology, Public Policy, and Law, 18, 1-17. doi:10.1037/a0024607

Fiske, S. T. (2002). What we know now about bias and intergroup conflict, the problem of the century. Current Directions in Psychological Science, 11, 123-128. doi:10.1111/14678721.00183

Fleischer, A., Mead, A. D., \& Huang, J. (2015). Inattentive responding in MTurk and other online samples. Industrial and Organizational Psychology: Perspectives on Science and Practice, 8, 196-202. doi:10.1017/iop.2015.25

Gazzaniga, M. (2011). Neuroscience in the courtroom. Scientific American, 304, 54-59.

Glenn, A. L., Iyer, R., Graham, J., Koleva, S., \& Haidt, J. (2009). Are all types of morality compromised in psychopathy? Journal of Personality Disorders, 23, 384-398. doi:10.1521/pedi.2009.23.4.384

Graham, J., Nosek, B., Haidt, J., Iyer, R., Koleva, S., \& Ditto, P. (2011). Mapping the moral domain. Journal of Personality and Social Psychology, 101, 366-385. doi:10.1037/a0021847

Haidt, J. (2001). The emotional dog and its rational tail: A social intuitionist approach to moral judgment. Psychological Review, 108, 814-834. doi:10.1037/0033-295X.108.4.814

Haidt, J. (2012). The righteous mind: Why good people are divided by politics and religion. New York, NY: Vintage Books.

Haidt, J. (2013). Moral psychology for the twenty-first century. Journal of Moral Education, 42, 281-297. doi:10.1080/03057240.2013.817327

Haidt, J., \& Graham, J. (2007). When morality opposes justice. Conservatives have moral intuitions that liberals may not recognize. Social Justice Research, 20, 
98-116. doi:10.1007/s 11211-007-0034-Z

Haidt, J., \& Joseph, C. (2004). Intuitive ethics: How innately prepared intuitions generate culturally variable virtues. Daedalus, 133, 55-66. doi:10.1162/0011526042365555

Hare, R. D., \& Neumann, C. S. (2008). Psychopathy as a clinical and empirical construct. Annual Review of Clinical Psychology, 4, 217-246. doi:10.1146/annurev.clinpsy.3.022806.091452

Ishida, C. (2006). How do scores of DIT and MJT differ? A critical assessment of the use of alternative moral development scales in studies of business ethics. Journal of Business Ethics, 67, 63-74. doi:10.1007/s10551-006-9005-9

Jonason, P. K., \& Kroll, C. H. (2015). A multidimensional view of the relationship between empathy and the dark triad. Journal of Individual Differences, 36, 150-156. doi:10.1027/1614-0001/a000166

Khvatskaya, Y., \& Lenzenweger, M. F. (2016). Motor empathy in individuals with psychopathic traits: A preliminary study. Journal of Personality Disorders, 30, 613-632. doi:10.1521/pedi_2015_29_219

Kohlberg, L. (1969). Stage and sequence: The cognitive-developmental approach to socialization. In D. A. Goslin (Ed.), Handbook of Socialization Theory and Research (pp. 347-480). Chicago, IL: Rand McNally

Kohlberg, L., Levine, C., \& Hewer, A. (1983). Moral stages: A current formulation and a response to critics. Basel, Switzerland: Karger.

Koleva, S., Selterman, D., Iyer, R., Ditto, P., \& Graham, J. (2013). The moral compass of insecurity: Anxious and avoidant attachment predict moral judgment. Social Psychological and Personality Science, 5, 185-194. doi:10.1177/1948550613490965

Lerkiatbundit, S., Utaipan, P., Laohawiriyanon, C., \& Teo, A. (2006). Impact of the Konstanz method of dilemma discussion on moral judgment in allied health students: A randomized controlled study. Journal of Allied Health, 35, 101-108.

Levy, N. (2008). The responsibility of the psychopath revisited. Philosophy, Psychiatry, \& Psychology, 14, 129-138. doi: http://dx.doi.org/10.1353/ppp.0.0003 
Lilienfeld, S. O., \& Hess, T. H. (2001). Psychopathic personality traits and somatization: Sex differences and the mediating role of negative emotionality. Journal of Psychopathology and Behavioral Assessment, 23, 11-24. doi:10.1023/A:1011035306061

Lilienfeld, S. O., Latzman, R. D., Watts, A. L., Smith, S. F., \& Dutton, K. D. (2014). Correlates of psychopathic personality traits in everyday life: Results from a large community survey. Frontiers in Psychology, 5, 1-11. doi:10.3389/fpsyg.2014.00740

Lilienfeld, S. O., \& Widows, M. R (2005). Psychopathic Personality Inventory-Revised. Lutz, FL: Psychological Assessment Resources, Inc.

Lind, G. (1978). How does one measure moral judgment? Problems and alternative ways of measuring a complex construct. In G. Portele (Ed.), Sozialisation und moral (pp. 171201). Weinheim: Beltz.

Lind, G. (1996, April). The optimal age of moral education. A review of intervention studies and an experimental test of the dual-aspect-theory of moral development and education. Paper presented at the SIG MDE, ERA meeting, New York, New York.

Lind, G. (1996). Testing moral judgment competence. A critical review of the attempt to calculate a C-score from the DIT. Retrieved from http://www.uni-konstanz.de/agmoral/pdf/Lind-1996_Kritik_Rest_C-score.pdf.

Lind, G.. (2005). The Cross-Cultural Validity of the Moral Judgment Test: Findings from 29 Cross-Cultural Studies. Paper presented at the American Psychological Association Annual Conference, Washington D.C.

Lind, G. (2014). The Moral Judgment Test. Retrieved from http://www.uni-konstanz.de/agmoral/material/moral/messen/MJT-eng9-revised-(c)-2015-Lind.pdf.

Lind, G., Hartmann, H. A., \& Wakenhut, R. (1985). Moral development and the social environment. Chicago, IL: Precedents Publishing.

Litton, P. (2007). Responsibility status of the psychopath: On moral reasoning and rational selfgovernance. Rutgers Law Journal, 39, 349-392.

MacCallum, R. C., Zhang, S., Preacher, K. J., \& Rucker, D. D. (2002). On the practice of dichotomization of quantitative variables. Psychological Methods, 7, 19-40.

Marcus, D. K., John, S. L., \& Edens, J. F. (2004). A taxometric analysis of psychopathic personality. Journal of Abnormal Psychology, 113, 626-635. doi:10.1037/0021843X.113.4.626

This article is protected by copyright. All rights reserved 
Marshall, J., Watts, A., \& Lilienfeld, S. (2016). Do psychopathic individuals possess a misaligned moral compass? A meta-analytic examination of psychopathy's relations with moral judgment. Personality Disorders: Theory, Research, and Treatment. doi:10.1037/per0000226.

M'Naghten's Case, 10 Clark, \& F 200, 8 Reprint 718. 1843.

Model Penal Code $\S$ 4.01. 1962.

Morse, S. J. (2008). Psychopathy and criminal responsibility. Neuroethics, 1, 205-212. doi:10.1007/s12152-008-9021-9

Nichols, S. (2002). How psychopaths threaten moral rationalism: Is it irrational to be amoral? The Monist, 85, 285-303. doi:10.5840/monist200285210

Packer, I. (2009). Evaluation of criminal responsibility. New York, New York: Oxford University Press, Inc.

Palmer, E. J. (2003). An overview of the relationship between moral reasoning and offending. Australian Psychologist, 38, 165-174. doi:10.1080/00050060310001707177

Preacher, K. \& Hayes, A. (2004). SPSS and SAS procedures for estimating indirect effects in simple mediation models. Behavior Research Methods, Instruments, and Computers, 36, 717-731. doi:10.3758/BF03206553

Prichard, J.C. (1835). A treatise on insanity and other disorders affecting the mind. London, England: Sherwood, Gilbert, and Piper.

Riopka, S. J., Coupland, R. A., \& Olver, M. E. (2015). Self-reported psychopathy and its association with criminal cognition and antisocial behavior in a sample of university undergraduates. Canadian Journal of Behavioural Science, 47, 216-225. doi:10.1037/a0039075

Skeem, J. L., Polaschek, D. L., Patrick, C. J., \& Lilienfeld, S. O. (2011). Psychopathic personality: Bridging the gap between scientific evidence and public policy. Psychological Science in the Public Interest, 12(3), 95-162. doi:10.1177/1529100611426706

Vitacco, M. J., Erickson, S., \& Lishner, D. (2013). Comment: Holding psychopaths morally and criminally culpable. Emotion Review, 5, 423-425. doi:10.1177/1754073913490043

\section{Table 1}

Descriptive Statistics and Alpha Reliability Coefficients for Administered Measures 


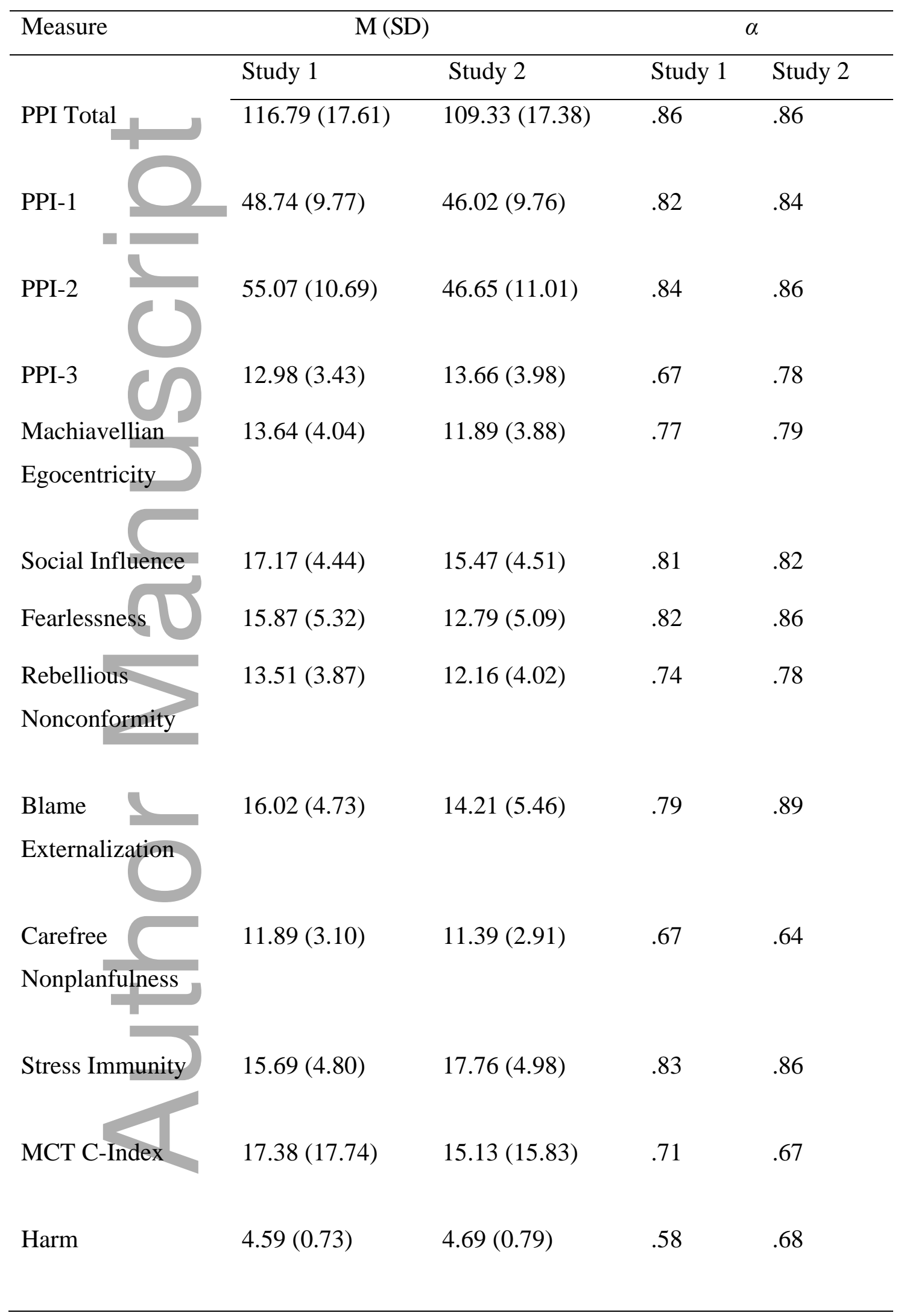




\begin{tabular}{lcccc}
\hline Fairness & $4.58(0.66)$ & $4.65(0.76)$ & .61 & .63 \\
In-group & $4.01(0.80)$ & $3.35(0.98)$ & .60 & .76 \\
& & & & \\
Authority & $4.19(0.73)$ & $3.78(0.99)$ & .56 & .73 \\
& & & .70 & .87 \\
\hline
\end{tabular}

Note: PPI-1 = Fearless Dominance Factor; PPI-2 = Self-Centered Impulsivity Factor; PPI-3 = Coldheartedness Factor

\section{Table 2}

Study One (Undergraduate Sample) Zero-Order Correlations Among Study Variables

\begin{tabular}{|c|c|c|c|c|c|c|c|c|}
\hline $\begin{array}{ll}\text { Variable } & 1 .\end{array}$ & 2. & 3. & 4. & 5. & 6. & 7. & 8. & 9. \\
\hline 1. PPI-Total & -- & -- & -- & -- & -- & -- & -- & -- \\
\hline 2. PPI-1 & -- & -- & -- & -- & -- & -- & -- & -- \\
\hline 3. PPI-2 & $.30 * * *$ & -- & -- & -- & -- & -- & -- & -- \\
\hline 4. PPI-3 $\quad .40 * * *$ & $.18^{*}$ & $.18^{*}$ & -- & -- & -- & -- & -- & -- \\
\hline 5. C-Index & -.02 & -.11 & -.03 & -- & -- & -- & -- & -- \\
\hline 6. Harm $-.29 * * * *$ & -.16 & -.16 & $-.56 * *$ & .03 & -- & -- & -- & -- \\
\hline 7. Fairness & .17 & $-.24 * *$ & $-.37 * * *$ & .12 & $.53 * * *$ & -- & -- & -- \\
\hline 8. In-group & $.18^{*}$ & -.04 & .01 & .02 & $.19 *$ & -.01 & -- & -- \\
\hline 9. Authority $\quad-.04$ & .02 & -.04 & -.12 & -.02 & $.19 *$ & .10 & $.63 * * *$ & -- \\
\hline 10. Purity $-.19 *$ & -.07 & $-.18 *$ & $-.22 * *$ & .05 & $.25 * *$ & .15 & $.49 * * * *$ & $.54 * * *$ \\
\hline
\end{tabular}

Note: PPI-1 = Fearless Dominance Factor; PPI-2 = Self-Centered Impulsivity Factor; PPI-3 = Coldheartedness Factor

This article is protected by copyright. All rights reserved 
$* \mathrm{p} \leq .05 ; * * \mathrm{p} \leq .01 ; * * * \mathrm{p} \leq .001$.

\begin{tabular}{|c|c|c|c|c|c|}
\hline Moral Intuition & 及eta & $\begin{array}{l}\text { 95\% Confidence } \\
\text { Interval (Lower } \\
\text { Limit) }\end{array}$ & $\begin{array}{c}\text { 95\% Confidence } \\
\text { Interval (Higher } \\
\text { Limit) }\end{array}$ & $\mathrm{Z}$ & $\begin{array}{c}\text { Significance } \\
\text { Test }\end{array}$ \\
\hline Harm & -.00 & -.06 & .05 & -.10 & .92 \\
\hline Fairness & -.03 & -.10 & .03 & -1.02 & .31 \\
\hline
\end{tabular}

\section{Table 3}

Study One - Moral Intuitions as Mediator between Psychopathic Traits and Moral Judgment Note: 5,000 Bootstrap Samples were utilized.

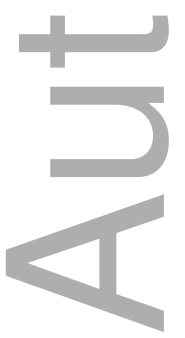




\begin{tabular}{llllll} 
In-group & .00 & -.02 & .02 & .21 & .83 \\
Authority & .00 & -.02 & .02 & .10 & .92 \\
Purity & -.01 & -.05 & .03 & -.30 & .76 \\
\hline
\end{tabular}

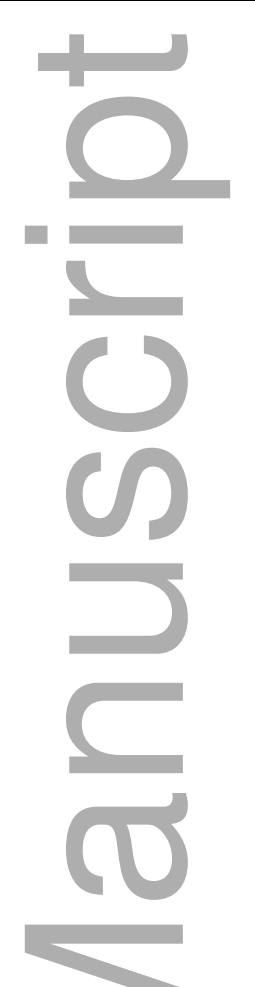

\section{Table 4}

Study Two (Community Sample) Zero-Order Correlations Among Study Variables

\begin{tabular}{|c|c|c|c|c|c|c|c|c|}
\hline 1. & 2. & 3. & 4. & 5. & 6. & 7. & 8. & 9. \\
\hline 1. PPI-Total & -- & -- & -- & -- & -- & -- & -- & -- \\
\hline 2. PPI-1 & -- & -- & -- & -- & -- & -- & -- & -- \\
\hline 3. PPI-2 & $.16^{*}$ & -- & -- & -- & -- & -- & -- & -- \\
\hline 4. PPI-3 & $.23 * * *$ & $.20 * *$ & -- & -- & -- & -- & -- & -- \\
\hline 5. C-Index & .09 & -.12 & -.01 & -- & -- & -- & -- & -- \\
\hline 6. Harm & $-.22 * * *$ & $-.18 * *$ & $-.54 * * *$ & .08 & -- & -- & -- & -- \\
\hline 7. Fairness & $-.22 * * *$ & -.07 & $-.43 * * *$ & $.15^{*}$ & $.63 * * *$ & -- & -- & -- \\
\hline
\end{tabular}


$\begin{array}{lllllllllll}\text { 8. In-group } & -.01 & -.02 & .03 & -.10 & \mathbf{- . 1 6 *} & .09 & -.00 & -- & --\end{array}$

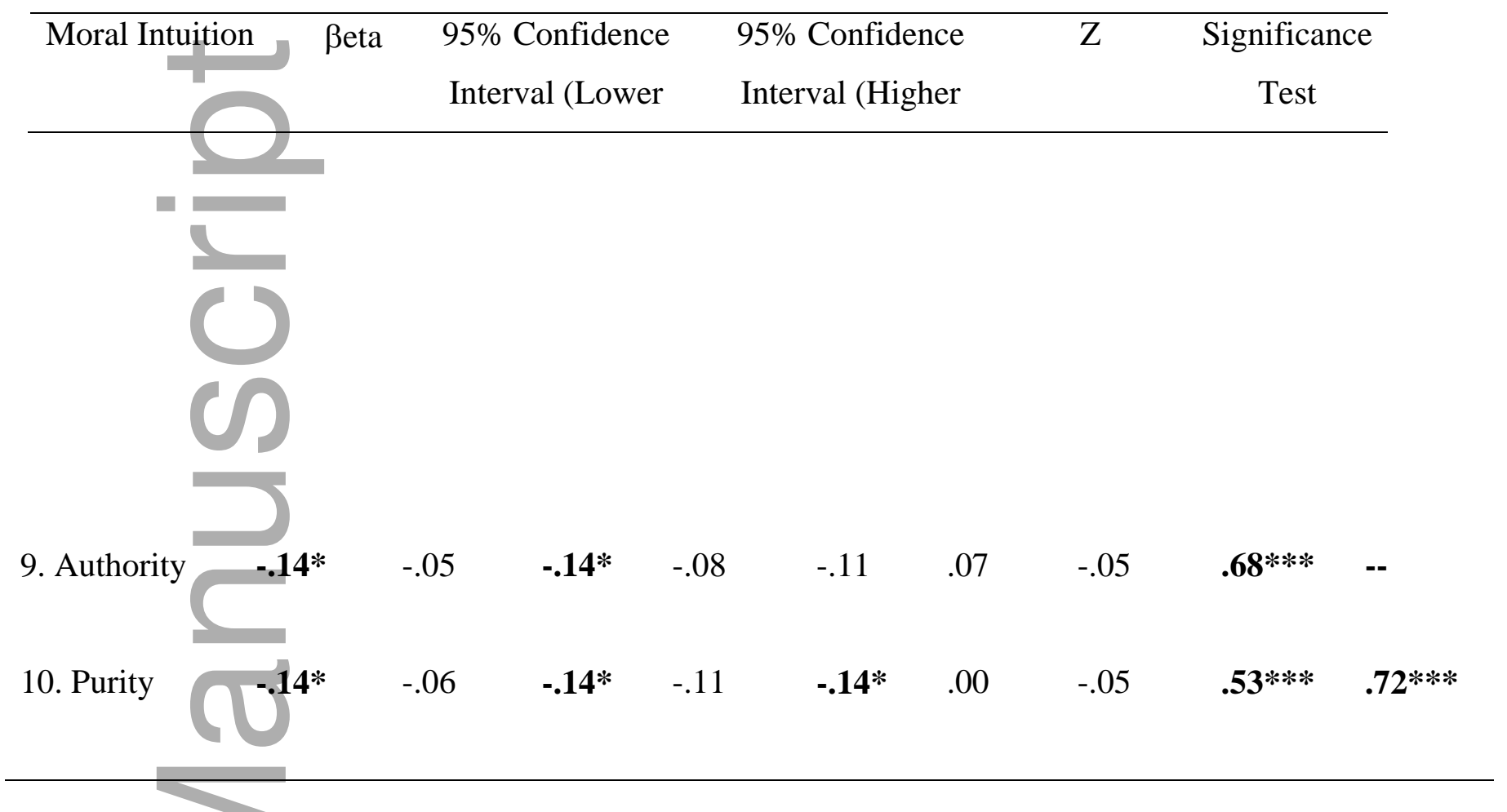

Note: PPI-1 = Fearless Dominance Factor; PPI-2 = Self-Centered Impulsivity Factor; PPI-3 = Coldheartedness Factor

$* \mathrm{p} \leq .05 ; * * \mathrm{p} \leq .01 ; * * * \mathrm{p} \leq .001$.

\section{Table 5}

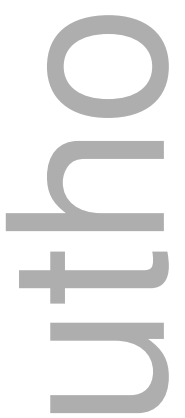

Study Two - Moral Intuitions as Mediator between Psychopathic Traits and Moral Judgment Note: 5,000 Bootstrap Samples were utilized. 


\begin{tabular}{lccccc}
\hline & & Limit) & Limit & & \\
& & & & & \\
\hline Harm & -.03 & -.07 & .02 & -.98 & .33 \\
Fairness & -.04 & -.08 & .00 & -1.82 & .07 \\
In-group & .00 & -.02 & .02 & .16 & .87 \\
Authority & .01 & -.01 & .04 & 1.16 & .25 \\
Purity & .02 & -.01 & .05 & 1.40 & .16 \\
\hline
\end{tabular}

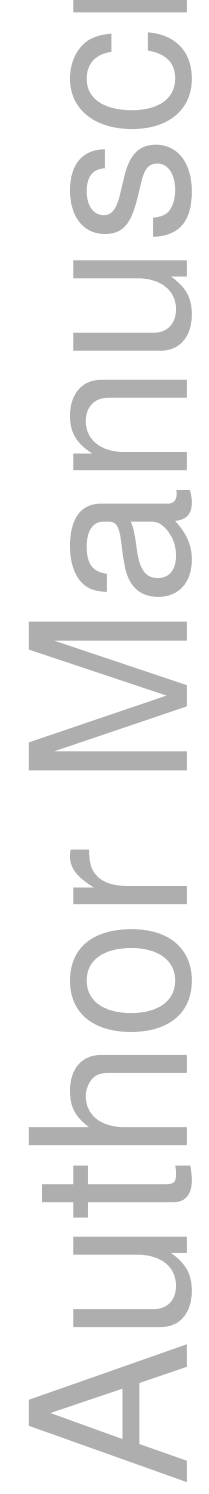

This article is protected by copyright. All rights reserved 


\section{University Library}

\section{- M M N E R VA A gateway to Melbourne's research publications}

Minerva Access is the Institutional Repository of The University of Melbourne

\section{Author/s:}

Gay, JG;Vitacco, MJ;Hackney, A;Beussink, C;Lilienfeld, SO

Title:

Relations among psychopathy, moral competence, and moral intuitions in student and community samples

\section{Date:}

2018-09-01

\section{Citation:}

Gay, J. G., Vitacco, M. J., Hackney, A., Beussink, C. \& Lilienfeld, S. O. (2018). Relations among psychopathy, moral competence, and moral intuitions in student and community samples. LEGAL AND CRIMINOLOGICAL PSYCHOLOGY, 23 (2), pp.117-134. https:// doi.org/10.1111/lcrp.12128.

Persistent Link:

http://hdl.handle.net/11343/283815 